\title{
HÁ EFETIVIDADE NA EXECUÇÃO FISCAL REALIZADA PELA JUSTIÇA ELEITORAL?
}

José Ezequiel Albuquerque Bernardino ${ }^{1}$

\section{RESUMO}

Tem-se como objetivo do presente artigo fazer uma abordagem do tema efetividade da execução fiscal no âmbito da Justiça Eleitoral, levando-se em consideração pesquisa realizada pelo Conselho Nacional de Justiça, que atesta um congestionamento processual das execuções fiscais desta Justiça Especializada, traçando um paralelo com a anistia da aplicação de multas eleitorais realizada pelo Congresso Nacional, dada a infringência da legislação eleitoral.

PALAVRAS-CHAVE: Justiça Eleitoral; Execução fiscal; Efetividade; Gargalo da execução; Multas eleitorais.

\section{IS EFFECTIVENESS ON TAX IMPLEMENTATION CARRIED OUT BY ELECTORAL JUSTICE?}

\begin{abstract}
The purpose of this article is to analyze the effectiveness of tax enforcement in the scope of the Electoral Justice, taking into account the research carried out by the National Council of Justice, which attests to a procedural congestion of the fiscal executions of this Specialized Justice, drawing a parallel to the amnesty of the application of electoral fines by the National Congress, given the violation of electoral legislation.
\end{abstract}

KEYWORDS: Electoral Justice; Tax enforcement; Effectiveness; Execution bottleneck; Electoral fines.

\section{CONSIDERAÇÕES INICIAIS}

O interesse pelo tema da efetividade da execução fiscal na seara da Justiça Eleitoral dá-se em razão da existência de um celeiro de possibilidades de aplicação de multas eleitorais no decorrer do percurso do processo eleitoral; o que, caso desempenhado eficientemente, atenderá à recuperação dos créditos públicos e, assim, viabilizará a concretização dos direitos fundamentais dos cidadãos.

Nesse contexto, impende registrar que há na literatura tributária o desleal axioma da vulnerabilidade da Fazenda Pública na condução das ações do Estado para a obtenção da

1Mestrando em Direito, Acesso à Justiça e ao Desenvolvimento pelo Centro Universitário Christus UNICHRISTUS. Assessor Jurídico do Tribunal Regional Eleitoral do Ceará. Bacharel em Direito pela Universidade de Fortaleza- UNIFOR. E-mail: ezequielbernardino7@gmail.com. 
receita e a realização dos gastos para o atendimento das necessidades públicas, de modo que, sob o pálio do interesse público, os operadores do direito por meio do sistema processual e dos Tribunais estariam obrigados a corrigir esta fragilidade estatal.

Não há dúvida que uma das formas de ingresso de receita pública para atingir os fins e os objetivos políticos e econômicos estatais, perpassa pela arrecadação das multas aplicadas na Justiça Eleitoral.

Desta forma, é curioso que diante deste rosário de perspectivas de recuperação dos créditos públicos e, a título exemplificativo, na jurisdição eleitoral; pode-se citar as multas por doação de campanha acima do limite legal, multas em face do exercício de propaganda eleitoral irregular, multa pela prática de conduta vedada, dentre outras, que ainda se veja argumentação de que o Estado se situe numa posição de debilidade.

Nessa esteira de raciocínio tem-se em contraponto à argumentação expendida a notícia da tramitação de projeto de lei de autoria do deputado Elmar Nascimento, do Partido Democratas (DEM) do estado da Bahia, o qual propõe a proibição das rejeições de contas e garante anistia de multa às agremiações que não gastaram a cota de $5 \%$ de recursos com programas de promoção e difusão da participação política das mulheres.

De fato, o projeto de lei foi votado e aprovado nas duas casas legislativas, Câmara e Senado, contudo houve apenas veto presidencial de um trecho da proposta normativa que anistiava doações de servidores públicos que ocupam cargos comissionados, sob a justificativa da limitação fiscal.

Apesar da referência a recente aprovação da lei de anistia mencionada no parágrafo antecedente, tal prática não é algo inédito, nem demonstra sua ocorrência de forma excepcional, de forma que o passado republicano é marcado pela edição de leis de anistia de multas aplicadas pela Justiça Eleitoral.

Contradizendo tal costume, o Conselho Federal da Ordem dos Advogados do Brasil ajuizou a ação direta de inconstitucionalidade n. ${ }^{\circ}$ 2306-3 - DF, que objetivou o afastamento do ordenamento jurídico nacional a lei 9.996/2000, que concedia anistia das multas eleitorais aplicados nos anos de 1996 e 1998, no entanto a pretensão por mais que se albergasse em 
vários princípios constitucionais, dentre eles o princípio da moralidade, foi julgada improcedente (BRASIL, 2002).

Com efeito, o paradoxo da matéria resume-se no questionamento feito no seio da mencionada ADI, em que o então Ministro Sepúlveda Pertence, pondera a ofensa desse processo legal de anistia, uma vez que votada pelos próprios eleitos e acabando por tornar inócua toda a administração eleitoral (BRASIL, 2002).

Em um segundo ponto, opta-se a discorrer sobre o procedimento da execução fiscal das multas eleitorais, uma vez que o tema vai envolver a efetividade da cobrança deste crédito público, dada a competência desta justiça especializada para processar e julgar execução fiscal proveniente de multa aplicada em consequência de infração do Código Eleitoral (BRASIL, 1965).

O terceiro ponto a ser abordado relaciona as possíveis causas de ineficiência estatal no trato da execução fiscal, onde serão abordados questões pertinentes à prescrição do crédito tributário, tema que termina por dificultar a percepção das receitas públicas e, por conseguinte desafiando o poder público a gerir seus orçamentos de forma a atender a crescente demanda dos direitos sociais.

\section{CONSIDERAÇÕES SOBRE O PROCEDIMENTO DA EXECUÇÃO FISCAL DAS MULTAS ELEITORAIS}

Diferentemente da cobrança de um crédito em que os particulares utilizam-se do Código de Processo Civil para satisfazer sua pretensão com base na execução de título extrajudicial, a Justiça Eleitoral vale-se da lei n. ${ }^{\circ}$ 6.830/80, dado que o próprio Código Eleitoral (lei n. ${ }^{\circ}$ 4.737/65) tratou de singularizar que a cobrança de qualquer multa será feita por ação executiva na forma prevista para a cobrança da dívida ativa da Fazenda Pública² (BRASIL, 1965).

2 "Art. 367. A imposição e a cobrança de qualquer multa, salvo no caso das condenações criminais, obedecerão às seguintes normas: (...) IV - A cobrança judicial da dívida ativa será feita por ação executiva na forma prevista para a cobrança da dívida ativa da Fazenda Pública, correndo a ação perante os juízos eleitorais.” 
No caso da Justiça Eleitoral, o que amparará o ensejo da execução fiscal serão as multas eleitorais, desde que inscritas em livro próprio na Secretaria do Tribunal, caso não pagar no prazo de trinta dias.

Nesse sentido, cabe ressaltar, ainda que se fale da avalanche de processos de execução fiscal, como um dos fatores preponderantes para ineficiência estatal, que se precisa levar em conta a simplificação dessa apuração administrativa de crédito, como um dos desentraves a favor da Fazenda Pública.

Há de ver-se que o significado do levantamento do crédito público realizado administrativamente reduz o tempo que disporá a Fazenda Pública com a realização dos atos processuais para a cobrança da dívida ativa, que será a fase ulterior, judicializada e com pontos de vista favoráveis e contrários à sua permanência no ordenamento jurídico brasileiro.

Note-se, portanto, que a execução fiscal, tal como a execução civil, só poderá iniciar a expropriação após a conjugação da certeza, liquidez e exigibilidade. O detalhe é que estes três requisitos serão conferidos na Justiça Eleitoral, somente após a realização deste procedimento administrativo mencionado no parágrafo antecedente.

Em arremate (TEODORO JUNIOR, 2017, p. 51) assevera que "o procedimento da lei n. ${ }^{\circ}$ 6.830/80 só será utilizada pela Fazenda Pública após a adequada apuração administrativa de seu crédito, seguida de inscrição em dívida ativa”.

Como visto não há nenhuma complexidade no trâmite. Resumindo: depois do trânsito em julgado da decisão ou acórdão que aplicou a multa eleitoral, não havendo o adimplemento, serão enviadas cópias do processo à Procuradoria da Fazenda Nacional, para inclusão do valor na dívida ativa da União.

Desta forma, o papel da execução fiscal consiste no ato de obtenção do adimplemento do crédito tributário, mas não de qualquer forma, a qualquer custo, contudo sempre tendo em conta o devido processo legal, que começa com a apresentação da inicial, cujas exigências cingem-se apenas a indicação do juiz a quem está se dirigindo, o pedido e o requerimento para a citação do acusado, bem como deve vir acompanhada da certidão da dívida ativa. 
Em sendo assim, resta assaz perceptível que tudo conspira a favor do bom desempenho da expropriação fiscal. A despeito, a demanda não carece ser instruída com o demonstrativo da dívida, como acontece numa execução por quantia.

Há de concluir-se, portanto, que há todo um aparato legal, em que se endossa a prescindibilidade da demonstração do cálculo da dívida, sendo igualmente confirmada por Súmula do STJ, a qual se transcreve, verbi: "Súmula 559: Em ações de execução fiscal, é desnecessária a instrução da petição inicial com o demonstrativo de cálculo do débito, por tratar-se de requisito não previsto no art. $6^{\circ}$ da Lei n. ${ }^{\circ} 6.830 / 80 . "$

De modo que esse procedimento fiscal é marcado por vários preceptivos que facilitam esta função estatal, havendo o diploma normativo, ainda propiciado à substituição ou emenda da CDA até o proferimento da sentença de primeira instância, o que em tese, evidencia mais um instrumento para consecução da recuperação do crédito público.

Contudo, apesar de todo a aparelhagem que a Fazenda Pública dispõe para consecução da finalidade expropriatória, há relatos de protestos da Procuradoria da Fazenda Nacional, pugnando pela mudança e aprimoramento da cobrança contenciosa da dívida ativa dos entes públicos. Nesse sentido assim se manifestou Carlos Francisco Lopes Melo (2012, p. 109) por meio de artigo acadêmico, a qual se transcreve trecho no que interessa:

Não obstante a Lei de Execução Fiscal ter sido fruto de laborioso trabalho realizado
pela Procuradoria-Geral da Fazenda Nacional, juntamente com representantes do
Instituto da Administração Financeira da Previdência e Assistência Social e da
Procuradoria-Geral da República, os resultados apresentados em menos de trinta
anos de sua vigência induzem à necessidade de mudança e ao aprimoramento da
cobrança contenciosa da dívida dos entes públicos e suas respectivas autarquias e
fundaçôes.

Neste diapasão, ao tomar como norte as premissas que encabeçaram a argumentação levada a efeito pelos agentes públicos encarregados da satisfação dos créditos públicos, cabe a indagação de se estas guardam pertinência com a conclusão da inefetividade estatal.

Por certo, a realidade fática sugere uma conjuntura a que Walton (2012, p.18) chamou de "diálogo persuasivo simétrico", porquanto existem vozes de peso na doutrina que não compartilham do mesmo entendimento no tocante a ineficiência expropriatória fiscal, apenas em razão da necessidade de aperfeiçoamento da lei de execução fiscal. 
Por oportuno, bastante conveniente é a opinião de Machado (2010), ferrenho opositor da proposta de lei da execução fiscal administrativa, quando repele a viabilidade da adoção desta nova roupagem, face a violação de vários princípios que modelam uma República nos termos de um Estado Democrático de Direito.

De outra banda, pode-se sugerir, sem a convicção de chegar a validade de uma conclusão, que restaria ausente diante das proposições apresentadas alguma premissa válida que deveria constar da argumentação no que se refere à execução fiscal das multas eleitorais; mas até o momento não foi tratada ou apenas foi ventilada com sutileza.

Diante das observações apresentadas, parece inapropriado, atípico, diria até maçante, falar-se da baixa efetividade desta tutela executiva, diante de todos instrumentos oferecidos ao Estado pela legislação fiscal e o reforço judicial disponibilizado por meio da referida súmula do STJ, que impede qualquer entendimento contrário à Fazenda Pública.

Isso porque a execução fiscal, classificada como espécie da execução por quantia certa, foi instituída por um Estado-Legislador; igualmente, a dívida ativa é cobrada por este mesmo Estado, na versão de Estado administrador, e é objeto de execução por uma terceira versão, o Estado-juiz (Tríplice atribuição do Estado).

Nesse sentido, traz-se a concepção do tríduo das atribuições nas próprias palavras de James Marins (2012, p. 79) para uma visualidade mais próxima da sua construção, vejamos:

A execução forçada dos bens do contribuinte configura a etapa mais invasiva da
relação entre Estado e cidadão. É o momento no qual o contribuinte,
independentemente de sua vontade, poderá perder para o Estado a posse e a
propriedade de seus bens ou direitos patrimoniais em razão da força executiva de um
título de crédito. Este vínculo, no entanto, foi instituído pelo Estado-legislador,
formalizado e cobrado pelo Estado-administrador e, finalmente, objeto de execução
pelo Estado-juiz.

Nessa esteira de pensamento, as ideias aqui apresentadas, seja por meio de doutrina balizada, seja por meio da confirmação dos Tribunais do aparato da lei de execução físcal a favor dos entes públicos; apenas apontam as tentativas realizadas pelos legisladores antecedentes no afã de tornar mais eficiente a trajetória da recuperação dos créditos públicos.

Indubitavelmente, a eficiência buscada pela legislação, sua concretude, não é objeto de realização na prática. Por isso, a ressonância de um avalizado número de críticas a respeito 
desta temática, que desafiam os trabalhos acadêmicos a externar uma perspectiva mais consentânea com esta função estatal.

Bem por isso que se mostra refratária a ideia da atuação dos magistrados como meras guias da máquina de cobrança estatal, que instrumentalizam a Fazenda Pública, exclusivamente por razões orçamentárias.

Mas, de fato, é inquestionável que os compromissos sociais abraçados pelo Estado brasileiro, sob a perspectiva da efetivação dos direitos fundamentais escriturados na Constituição Federal, necessitam de uma resposta financeira para subvencionar tais direitos, exigindo uma maior efetividade da execução fiscal para condução dos aportes das receitas públicas ao seu orçamento.

\section{CAUSAS APONTADAS COMO FATOR DE INEFICIÊNCIA DA EXECUÇÃO FISCAL}

A morosidade da tramitação dos processos no âmbito judicial é um dos fatores habitualmente citados na doutrina tributária como causa da ineficiência do serviço prestado pelo Judiciário.

O relatório editado pelo CNJ “Justiça em Números 2018” (2018, Online), prefaciado pela então presidente deste órgão do Judiciário, Ministra Carmen Lúcia, confirma tal assertiva quando assim descreve a chaga judicial:

Tem-se, no relatório, os problemas que precisam ser resolvidos para a prestação da
jurisdição em tempo razoável, como constitucionalmente assegurado ao cidadão.
Principalmente, busca-se entender em que áreas o Poder Judiciário há de atentar
prioritariamente para sua mudança em benefício do jurisdicionado, por ser
indiscutível que a tardia prestação jurisdicional é inaceitável. Demonstram-se,
também, as dificuldades com que lida o Judiciário, com volume de processos e
modelo de legislação processual que adia a finalização dos casos submetidos à
jurisdição.

Neste sentido, o relatório do Conselho Nacional de Justiça (2018) apresenta números preocupantes, o que o fez merecer sua separação compartimentada no item 4.3, o qual foi adjetivado por gargalo da execução. 
Isso porque a maior taxa de congestionamento de execução fiscal situa-se na Justiça Federal, representando 94\%; contudo, a percentagem representa o menor valor no tocante à Justiça Eleitoral, menor taxa em termos comparativos com a Justiça Federal, mas ainda representando $74 \%$ do congestionamento processual (CNJ, 2018).

De forma que pelas proporções retratadas, não se põe em xeque a contrariedade do poder público para recuperar seus créditos públicos, porque segundo pesquisa realizada pelo Termo de cooperação Técnica n. ${ }^{\circ}$ 02/2010, firmado entre o Instituto de Pesquisas Econômicas aplicadas (IPEA) e o Conselho Nacional de Justiça (CNJ), apenas três quintos dos processos de execução fiscal vencem a etapa de citação.

Há de se concluir que vinte por cento dos processos de execução fiscal não ultrapassaram a fase inicial da demanda fiscal, contudo, do estudo mencionado não se depreende que nenhuma proposição decorre de algum desvelo realizado pela instrução administrativa.

Afirma também a pesquisa que o grau de sucesso das ações de execução fiscal é relativamente alto, uma vez que em $33,9 \%$ dos casos a baixa dos processos verificam-se pelo pagamento integral da dívida, índice que se eleva para $45 \%$ quando a citação pessoal é exitosa $^{3}$ (CNJ, 2009).

De fato, os números confirmam esta indesejável e problemática realidade, assunto também retratado em artigos acadêmicos, que em síntese revelam a ineficácia do modelo de execução fiscal adotado no Brasil.

Assim retratou Carlos Francisco Lopes Melo (2012, Online), em termos matemáticos:

Ainda segundo a PGFN, existem cerca de 2,5 milhões de execuções fiscais no âmbito da Justiça Federal, enquanto que os dados do Conselho da Justiça Federal, em seu relatório "Justiça em Números", revelaram que até o dia 30 de setembro de 2002 existiam aproximadamente 1,7 milhões de execuções fiscais em tramitação na Justiça Federal de primeiro grau, o que revela a perspectiva de crescente acúmulo dos feitos executivos nos órgãos judiciais nacionais.

Em sentido diverso e bastante convincente, é a opinião da Procuradora da Fazenda Nacional, Simone Anacleto, que desmistificando toda argumentação até aqui engendrada,

3 Dados obtidos do Relatório Justiça em números referentes ao ano de 2009 e contidos na produção interna do CNJ: "A execução fiscal no Brasil e o impacto no judiciário." 
revela o engano de denominar a lei n. ${ }^{\circ}$ 6.830/80 de ineficiente, apresentando também outro horizonte em relação a problemática da arrecadação dos créditos públicos. Eis, em síntese, seu pensamento (2015, Online):

A dívida ativa não existe isoladamente. Pelo contrário, ela se insere no sistema de cobrança dos créditos tributários, que começa na constituição dos créditos tributários e, normalmente, termina no pagamento desses créditos. No caso da União, em 2014, a dívida ativa superou, em muito, a espantosa cifra de um trilhão de reais, mas a arrecadação ficou aquém de $2 \%$ desse total. Não obstante, há que se ter em mente que apenas uma parcela, relativamente pequena, do total dos créditos tributários constituídos não é mesmo paga ou parcelada e acaba inscrita em dívida ativa.

Diante da desconstrução das premissas anteriormente relacionadas, depreende-se que, apesar de todo o estudo realizado, a realidade ressente-se de mais elementos que possam diagnosticar a problemática da arrecadação do crédito público; ou seja, o exame de ressonância não captou de forma completa os pontos cegos do direito nesta temática.

Outro agente apontado como razão da inefetividade fiscal relaciona-se com a prescrição, que iniciará sua contagem ao final de cinco anos; quando não forem encontrados bens passíveis de penhora, o juiz suspende a execução e ordena o arquivamento dos autos.

Por tal instituto, por mais desfavorável que seja para o credor público, haverá a decretação da prescrição, porquanto não admissível a tese de dívidas imprescritíveis, subvertendo o princípio fundamental da segurança jurídica.

Convém-se anotar a sensível elucidação de Hugo Machado Segundo (2018, p. 325), quando afiança a ocorrência da prescrição, fundamentando-se em julgamentos do Superior Tribunal de Justiça:

Seja como for, o importante é perceber que não pode haver dívidas imprescritíveis. Arquivado o processo de execução, e permanecendo arquivado por cinco anos, com a completa inércia da Fazenda exequente, não é possível considerar-se suspensa também a prescrição, em ofensa ao princípio geral da prescritibilidade das obrigações, decorrente do princípio fundamental da segurança jurídica. Raciocinando assim, o STJ entende que não há invalidade nas disposições do art. 40 da Lei n. ${ }^{\circ}$ 6.830/80 a respeito da prescrição, desde que sejam interpretadas em consonância com o art. 174 d0 CTN. Essa interpretação harmônica conduz à conclusão de que a prescrição mantem-se suspensa por um ano, enquanto suspensa se mantiver a execução, mas inicia-se novamente tão $\log o$ escoado este um ano e arquivada a execução fiscal. 
Quanto ao ponto, alerta-se que o fator da prescrição não deveria ser imputado à Fazenda Pública Federal, porquanto encontra-se com sua estruturação bem mais organizada em comparação aos entes municipais, dada a dependência histórica dos repasses dos recursos dos Estados e da União.

Nessa ordem de ideias, traz-se ao debate, como fator desencadeante da inefetividade da execução fiscal na Justiça Eleitoral, a anistia concedida pelo Congresso Nacional às multas aplicadas pela Justiça Eleitoral.

Nessa senda é cabível registrar a conceituação da anistia como o esquecimento da infração cometida à legislação e suas consequências jurídicas. É certo que a execução fiscal eleitoral não se trata de dívida tributária, relaciona-se com as dívidas não tributárias. Mesmo assim, convém valer-se do escólio de Ricardo Lopes Torres (2011, p. 318), ao empregar o sentido do instituto:

\footnotetext{
Anistia é o esquecimento da infração cometida à legislação tributária e o perdão da multa ainda não aplicada. Dela cuida o CTN nos arts. 180 a 182. A terminologia empregada pelo legislador nem sempre é muito rigorosa e se torna encontradiça a expressão "cancelamento de débitos fiscais", que envolve a remissão do crédito correspondente à penalidade pecuniária já aplicada, enquanto a anistia atua sobre a própria infração e suas consequências jurídicas ainda não descobertas nem sancionadas.
}

Idêntico sentido também se percebe na consideração levada a efeito por Harada (2017, p. 668), contudo, denota-se uma postura mais firme e de negação à ocorrência do instituto, ao asseverar que muitos criticam esta forma de exclusão do crédito público, porque, utilizado com frequência, concorre para a consolidação de uma postura negativa, afetando o princípio da justiça fiscal.

Tomado o entendimento pela ótica do Direito Eleitoral, tudo parece confirmar que a prática do instituto iniludivelmente é utilizada com frequência pelos próprios congressistas, a exemplo do que ocorreu com a lei n. ${ }^{\circ}$ 9.996/2000, que concedeu anistia às multas eleitorais aplicadas nos anos de 1996 e 1998, reiterando-se semelhante postura rejeitável com a aprovação de lei, cuja proposição abarcou a proibição das rejeições de contas e garantiu a anistia de multa às agremiações que não gastaram a cota de 5\% de recursos com programas de promoção e difusão da participação política das mulheres (BRASIL, 2000). 
Nessa quadra, não há como deixar feridas à legalidade e ao devido processo legal, sendo por certo que Segundo $(2019$, p. 21) pondera que "a legalidade impõe-se nas relações processuais como nos atos do Poder Público de uma maneira geral”.

Igual percepção já teve manifestação, inclusive, no voto proferido pelo então Ministro Sepúlveda no julgamento da Ação Direta de Inconstitucionalidade n. ${ }^{\text {o } 2306-3 ~-~ D F, ~}$ quando levantou-se em desfavor da subversão da legalidade (BRASIL , 2002).

De certo que não vivemos em um estado de exceção; melhor esclarecendo, resta impossível ao legislador ordinário estabelecer exceção a um princípio que tem cadeira cativa na Constituição, de modo que as exceções ao princípio da Legalidade compreendem exatamente, rigorosamente, aquelas previstas na Constituição Federal (MACHADO, 2009, p. 48).

Há de se ver que a prioridade da Constituição, como norma fundamental do Estado, trata-se de tema que se desenvolveu com a Revolução Francesa, para se contrapor aos poderes do monarca, sob a égide do absolutismo dos monarcas; por este motivo, não converge a ideia de contingenciamento do absolutismo dos monarcas, para os legisladores da República, com os ideais republicanos.

Neste sentido, Bercovici (2003, p. 79) define que "embora liberais, as Constituições não serão, ainda, democráticas. E, mais importante, a Constituição não é do rei ou do povo, a Constituição é do Estado, assim como o direito é direito positivo, posto pelo Estado. E a Teoria da Constituição, um capítulo da Teoria Geral do Estado.”

Com efeito, a proposição legislativa de anistia das multas eleitorais aplicadas pela Justiça Eleitoral e posteriormente votada e aprovada pelos próprios legisladores que infringiram a legislação eleitoral, intercala o próprio diálogo da questão da inefetividade da arrecadação dos créditos públicos.

Qualquer argumentação nesse sentido se verá extirpada de qualquer debate legislativo, dada a maioria tirânica parlamentar não externar, ao agir desta forma, nenhuma inquietação com uma receita pública que deveria ser direcionada ao orçamento público, mas, que em razão do alvedrio parlamentar, não termina o seu percurso legal. 
Isso equivale a afirmar, secundado na argumentação de Hart (2009), que as normas jurídicas também se aplicam aos seus criadores; ou seja, a legislação eleitoral que estabeleceu que à transgressão de determinado preceptivo no percurso eleitoral, seria infligida multa eleitoral, também é dirigida ao próprio legislador.

Tal argumentação é chamada, pelo adversário das ideias de Austin, como argumento de âmbito de aplicação; distinguindo-se do conceito de ordem, uma vez que a ordem não é aplicável a si mesmo. Por esta razão, a ordem não é aplicada aos congressistas, mas à norma jurídica estampada na Constituição; a saber. a legalidade e o princípio do devido processo legal legislativo, a eles devem ser aplicados ${ }^{4}$ (LEAL, 2019).

\section{CONCLUSÃO}

A exposição de motivos da lei 6.830/80 demonstra que trata-se a norma de um modo de execução destinada à Fazenda Pública, cujo objetivo demasiado resume-se a brindar a máquina estatal com diversos instrumentos que pudessem encurtar o trajeto da recuperação do crédito público.

À época, os mecanismos de aparato estatal criados para solução da problemática foram acolhidos, mas a norma, com a evolução do tempo, tornou-se uma lei de meia-idade, que começou a se queixar de todas as modificações que ocorreram no seu parente próximo, o Código de Processo Civil.

Neste caminho repleto de obstáculos para o atingimento dos créditos fiscais, situa-se a problemática da execução fiscal; sobretudo a da Justiça Eleitoral, que, igualmente com a execução fiscal comum, reclama do abarrotamento de processos que não conseguem êxito na batalha de angariar ao Estado estes recursos, que vão se prestar a cumprir as finalidades públicas.

O relatório da Justiça em números 2018, produzido pelo $\mathrm{CNJ}$, confirmam as incertezas das dificuldades da execução fiscal na Justiça Eleitoral, tocando a esta justiça

4 Ideia retirada da síntese do Seminário, realizado nos dias 11 a 13 de abril na Universidade Unichristus, proferido pelo professor visitante André Cordeiro Leal sobre a Teoria do Direito Contemporâneo, focando-se no debate de Ronald Dworkin versus o filósofo britânico, Herbert Lionel Adolphus Hart. 
especializada o congestionamento de $74 \%$ da quantidade de processos, revelando também sua inefetividade, tal qual a Justiça Federal, com 94\% de congestionamento processual; o que fez por ganhar, pela pesquisa realizada pelo Conselho Nacional, o subtítulo de gargalo da execução.

Tendo em conta toda a sorte de tribulações que se ressente a execução fiscal na recuperação fiscal, soma-se a esta chaga judicial a anistia das multas eleitorais aplicadas no processo eleitoral, que de forma não republicana tem o seu esquecimento determinado pelos atores parlamentares envolvidos nas infrações da legislação eleitoral.

De forma que, toda argumentação construída, em que se sustenta na dificuldade da recuperação das receitas públicas, sofre influência negativa do próprio Estado, o Estado legislador, nas pessoas dos deputados e senadores que compõem o órgão legislativo, que se acham imunes à aplicação da legislação que eles próprios produzem.

A ausência de correção desta mencionada falta de postura demonstra uma falácia na argumentação da inefetividade da execução fiscal, em que por certo não se chegará a uma conclusão pertinente, dada a existência de premissas falsas, no sentido de que somente a quantidade de processos de execução fiscal seria o gargalo da recuperação das receitas públicas.

Com efeito, o Estado tem compromissos sociais e por isso vai se socorrer dos créditos fiscais para abastecer os cofres públicos, cuja finalidade primeira passa pelo atendimento das necessidades públicas; contudo, para um real diagnóstico do problema que atinge a efetividade da execução fiscal como um todo, necessário se faz a passagem de um aprofundamento crítico de todos os protagonistas que compõem o Estado administrador, o Estado legislador e o Estado juiz.

\section{REFERÊNCIAS}

ANACLETO, Simone. Projetos sobre dívida atíva e execução fiscal têm premissas equivocadas. 2015. Disponível em: https://www.conjur.com.br/2015-nov-11/simoneanacleto-pl-divida-ativa-premissas-equivocadas. Acesso em: 23 jun. 2019. 
BERCOVICI, Gilberto; MORAES FILHO, José Filomeno de; LIMA, Martonio Mont'alverne B. Teoria da Constituição: Estudos sobre o lugar da política no direito constitucional. Rio de Janeiro: Lumen Juris, 2003.

BRASIL. Constituição (1988). Constituição Federal de 1988. Brasília. Disponível em: http://www.planalto.gov.br/ccivil_03/constituicao/constituicao.htm. Acesso em: 11 jun. 2019

BRASIL. Lei no 4.737, de 15 de julho de 1965. Código Eleitoral. Brasília. Disponível em: http://www.planalto.gov.br/ccivil_03/leis/14737.htm. Acesso em: 19 jun. 2019.

BRASIL. Lei $\mathrm{n}^{\circ}$ 6.830, de 22 de setembro de 1980. Cobrança Judicial da Dívida Ativa da Fazenda Pública. Brasília. Disponível em: http://www.planalto.gov.br/ccivil_03/leis/16830.htm. Acesso em: 23 jun. 2019.

BRASIL. Lei n ${ }^{\text {9.996, de }} 14$ de agosto de 2000. Anistia de Multas Aplicadas Pela Justiça Eleitoral em 1996 e 1998. Brasília. Disponível em: http://www.planalto.gov.br/ccivil_03/Leis/L9996.htm. Acesso em: 23 jun. 2019

BRASIL. Superior Tribunal de Justiça. Súmula no 559. Brasília. Disponível em: https://www.legjur.com/sumula/busca?tri=stj\&num=559. Acesso em: 23 jun. 2019.

BRASIL. Supremo Tribunal Federal. Ação Direta de Inconstitucionalidade no 2.306. Brasília, 2002. Disponível em: https://stf.jusbrasil.com.br/jurisprudencia/14748819/acaodireta-de-inconstitucionalidade-adi-2306-df. Acesso em: 23 jun. 2019.

CNJ. Conselho Nacional de Justiça. Justiça em números 2009. 2009. Disponível em: http://www.cnj.jus.br/pesquisas-judiciarias/justicaemnumeros/2016-10-21-13-13-04/pjjustica-em-numeros. Acesso em: 23 jun. 2019.

CNJ. Conselho Nacional de Justiça. Justiça em números 2018. 2018. Disponível em: http://www.cnj.jus.br/files/conteudo/arquivo/2018/08/44b7368ec6f888b383f6c3de40c32167.p df. Acesso em: 23 jun. 2019.

HARADA, Kiyoshi. Direito Financeiro e Tributário. 26. ed. São Paulo: Atlas, 2017.

HART, Herbert L. A .O conceito de direito / H.L.A. Hart; pós-escrito organizado por Penelope A. Bulloch e Joseph Raz; tradução de Antonio de Oliveira Sette-Câmara; revisaõ de traduçaõ Marcelo Brandão Cipolla; revisão técnica Luiz Vergílio Dalla-Rossa. São Paulo: Editora WMF Martins Fontes, 2009. 
LEAL, André Cordeiro.Teoria do Direito Contemporâneo. Fortaleza, Unichristus, 2019. (Comunicação oral)

MACHADO, Hugo de Brito. Direitos Fundamentais do Contribuinte e a efetividade da jurisdição. São Paulo: Editora Atlas, 2010.

MARINS, James. Defesa e vulnerabilidade do contribuinte. São Paulo: Dialética, 2012.

MELO, Carlos Francisco Lopes. Execução fiscal administrativa à luz da Constituição Federal. Revista da Agu, Brasília, v. 31, n. 01, p.109-142, 2012. Disponível em: file://C:/Users/gabri/Downloads/127-464-1-PB.pdf. Acesso em: 23 jun. 2019.

SEGUNDO, Hugo de Brito Machado. Processo Tributário. 11. ed. Rio de Janeiro: Atlas, 2018.

THEODORO JÚNIOR, Humberto. Lei de execução fiscal. 13. ed. São Paulo: Saraiva, 2016.

TORRES, Ricardo Lobo. Curso de direito financeiro e tributário. 18 ed. Rio de Janeiro: Renovar, 2011.

WALTON, Douglas N.. Lógica Informal: Manual de argumentação Crítica. São Paulo: Martins Fontes, 2012. 